\title{
Nos batuques dos quintais: as compreensôes dos povos de Umbanda sobre saúde, adoecimento e cuidado
}

\author{
I ' Matheus Barbosa da Rocha, ${ }^{2}$ Ana Kalliny de Sousa Severo, \\ ${ }^{3}$ Antônio Vladimir Félix-Silva I
}

Resumo: Durante o processo de escravização africana

1 Universidade Federal do Piauí, Psicologia. Parnaíba-PI, Brasil no Brasil, os negros trouxeram consigo uma imensa bagagem simbólico-cultural, tais como danças, comidas, festividades e cerimônias religiosas. $\mathrm{Na}$ esfera religiosa, o processo de intercâmbio das doutrinas africanas com os elementos culturais já existentes em terras brasileiras deu surgimento à religião umbandista. $\mathrm{O}$ presente artigo teve como objetivo conhecer as concepçóes dos praticantes (matheusbr.psico@live.com). ORCID: 0000-0003-2483-1100

${ }^{2}$ Universidade Federal do Rio Grande do Norte. Natal-RN, Brasil (akssevero@gmail.com). ORCID: 0000-0002-9548-6394

${ }^{3}$ Universidade Federal do Piauí, Medicina. Parnaíba-PI, Brasil (wladyfelix@hotmail.com). ORCID: 0000-0003-3084-379X e consulentes de três terreiros de Umbanda sobre saúde, adoecimento e cuidado. Como matriz metodológica, utilizou-se o referencial da Análise Institucional "no papel". Os participantes foram três sacerdotes umbandistas e os respectivos praticantes e consulentes dos terreiros que os mesmos conduziam. Como resultados, identificamos alguns elementos que explicariam, de acordo com as cosmologias umbandistas, os processos de saúde/doença: desequilíbrios energéticos; pensamentos e condutas negativas diante da vida; nervosismo; obsessores; mediunidade não resolvida ou alguma questão de ordem médica ou psicológica. Pôde-se perceber, portanto, que os conhecimentos dos povos umbandistas sobre saúde em muito destoam daqueles em que se sustentam os saberes hegemonicamente instituídos que direcionam os profissionais da saúde.

> Palavras-chave: religiões afro-brasileiras; cosmologia; saúde; doença; cuidado.

Recebido em: 20/12/2018 Revisado em: 18/05/2019 Aprovado em: 23/05/2019 


\section{Introdução}

Este artigo - recorte da pesquisa de mestrado "Nos Batuques dos Quintais: As interfaces do cuidado em saúde entre religiōes de terreiros e Equipes de Saúde da Família” - traz como campo de problematização as concepçôes sobre saúde, adoecimento e cuidado dos praticantes ${ }^{1}$ e consulentes $^{2}$ de três terreiros ${ }^{3}$ de Umbanda de uma cidade do interior do Piauí.

Nesse aspecto, um primeiro elemento importante para trazermos às nossas problematizaçôes diz respeito ao fato de que, até o século XV, o continente africano era composto majoritariamente por diversas naçôes ou tribos, cada uma com suas próprias etnias, costumes, crenças e tecnologias. Com a chegada dos portugueses à regiáo, estes terminaram por se aproveitar do modo de organização tribal instituído pela população nativa, objetivando incentivar guerras entre os diferentes grupos culturais que lá existiam. Os vencidos eram colocados à venda ou trocados com os europeus por produtos necessários e apreciados pelos africanos, como sal e cachaça (BARROS, 2009).

Com essa artimanha, os portugueses passaram a utilizar o trabalho destes povos como mão de obra escravizada em Cabo Verde, São Tomé e Madeira e, a partir de 1535, nos engenhos ou usinas de cana-de-açúcar do Nordeste brasileiro (SCHWARCZ; STARLING, 2015). Posteriormente, com o passar dos séculos, também vieram a instituir o trabalho de tais sujeitos tanto nos garimpos de ouro de Minas Gerais quanto nas lavouras de café, localizadas nos interiores de São Paulo e Rio de Janeiro. Para chegar ao Brasil, esses povos eram exportados em navios negreiros, conhecidos por possuírem insalubres condiçōes para se viver, o que culminava em uma dizimação dos negros já durante a viagem.

Ao chegarem ao Brasil, os negros se depararam com uma sociedade instituída pelo teor aristocrata e escravista, atribuindo àqueles oriundos da África um valor mercadológico de compra e venda, assim como qualquer outro produto. Para legitimar seu poder, tal sistema fazia uso da coerção, bem como da violência física, psicológica e de diversos outros tipos de humilhaçôes (CASTRO, 2012). Desse modo, eram frequentes situaçôes em que os chamados "capitães do mato" "açoitavam em um tronco os escravizados fugitivos ou desobedientes.

É preciso ressaltar que quando estes chegaram ao Brasil, a responsabilidade de catequizá-los passou a ser de seus donos, já que os mesmos não eram considerados 
dignos de serem catequizados pelos padres jesuítas, como acontecia com os nativos brasileiros. Com isso, instituiu-se um processo de educação religiosa em que os "senhores de engenho"5 se responsabilizavam pela iniciação cristã dos escravos sobre sua tutela (RIBEIRO, 2012), algo que uma ou duas chicotadas muito bem resolveria.

Diante desse cenário, os sujeitos escravizados organizaram uma série de movimentaçôes contra essa dominação, como fugas, boicotes ao trabalho, organizaçôes de quilombos ${ }^{6}$ e preservação dos seus principais elementos culturais, tais como dialetos, cantigas, danças e religiōes. Contudo, estas últimas, em determinados casos, passaram a se instituir de modo camuflado (FREITAS, 2012), principalmente por causa de tais práticas sagradas terem sido consideradas, por muito tempo, como pecaminosas pela Igreja Católica e como comportamentos desviantes pela Coroa Portuguesa (e depois pelo Império Brasileiro) (RODHE, 2009).

Desse modo, os africanos que aqui se encontravam começaram a incorporar em seus rituais elementos simbólicos oriundos de outras culturas, como as tradiçôes orais (ameríndia, congo e iorubá) ${ }^{7}$ e escrita (portuguesa e espírita), bem como as dos malês, da maçonaria, do orientalismo, dos ciganos, do vegetalismo e da medicina popular (RODHE, 2009). Além disso, imagens e estátuas católicas se tornaram cada vez mais frequentes em determinados segmentos dos terreiros, incorporando-se com os elementos das culturas africanas que já estavam instituídos na África antes mesmo da diáspora negra, como os Orixás ${ }^{8}$ (JENSEN, 2001).

Esta união proporcionou uma movimentação constituinte de troca de costumes, crenças, saberes e conhecimentos sobre a natureza, diálogos estes que, apesar de coercitivos, já que se configuraram em um contexto de colonização, foram de grande importância para a institucionalização de uma nova religião, a Umbanda (BARROS, 2009). Trata-se, portanto, de uma religiáo oriunda de terras brasileiras que, em seu processo histórico, incorporou elementos, símbolos e ritos religiosos de diferentes culturas, tais como a do catolicismo, dos saberes indígenas e de algumas tribos africanas, do espiritismo, da medicina popular, dentre outros.

É tomando como base esta afirmação que percebemos em ritos religiosos de escravos do século XVIII algumas das características que hoje encontramos instituídas na Umbanda, tais como: a influência do Cristianismo, a capacidade de incorporar divindades de diferentes categorias e a presença de música percussiva e de danças rituais (RODHE, 2009). 
De modo geral, em tais estabelecimentos religiosos, historicamente têm sido ofertadas práticas de cuidado em saúde para questôes de ordem física, psicológica, espiritual ou problemas do cotidiano (SILVEIRA, 2014). Podemos perceber, portanto, que apesar de o Brasil ser constituído em sua maioria por fiéis, declaradamente, da Igreja Católica, sempre foram infindáveis os casos de cuidado em saúde ofertados por terreiros de Umbanda, em decorrência de problemas de ordem cotidiana como doenças, desempregos ou amores mal resolvidos. Nesse sentido, os líderes religiosos de tais crenças historicamente têm sido procurados para lidar com os mesmos sintomas trabalhados, em determinadas circunstâncias, pelos profissionais da saúde (MELLO; OLIVEIRA, 2013).

Percebemos, portanto, a importância de que os profissionais da saúde estabeleçam interfaces nas ofertas de cuidado com os aspectos simbólico-culturais concernentes à população negra, como é o caso das religióes de terreiros, e, de modo mais específico, a Umbanda. Torna-se necessário que nós, enquanto profissionais da saúde, passemos a compreender em maior profundidade em quais cosmologias tais religiōes estão inseridas, para que, a partir daí, possamos mergulhar nas compreensóes desses povos sobre saúde, adoecimento e cuidado.

No campo da pesquisa em saúde, essa realidade ainda precisa ser mais bem desenvolvida, já que ainda são praticamente inexistentes as investigaçóes sobre a Umbanda que se proponham a analisar as compreensóes dos seus adeptos e consulentes sobre os fenômenos de saúde-doença, já que, na maioria das vezes, tais estudos se debruçam ora nas especificidades das divindades e Orixás cultuados na referida religião, ora se propóem a estudar as configuraçôes do cuidado em saúde nesses estabelecimentos sagrados, conforme também almejaram alguns autores anteriores a esse estudo, como foi o caso de Gomes (2010), Mota e Trad (2011), Mello e Oliveira (2013), Rios et al. (2013) e Silva, Fernandez e Sacardo (2017). Também podemos citar as produçôes de Estélio Gomberg (2011) e de Miríam Cristina Rabelo (2018), ambos pesquisadores que se detêm em estudar a antropologia das religióes afro-brasileiras e, consequentemente, suas práticas de cuidado em saúde e outros aspectos que são peculiares às referidas doutrinas sagradas.

Assim, o presente estudo teve como objetivo compreender as concepçóes sobre saúde, adoecimento e cuidado dos praticantes e consulentes de três terreiros de Umbanda de uma cidade do interior do Piauí. 


\section{Percurso metodológico}

Neste artigo, trabalhamos com a pesquisa qualitativa, na modalidade empírica, que é aquela que convida o pesquisador a voltar seu olhar para os acontecimentos do campo. Como matriz de investigação e como estratégia de produção e análise das informaçóes, adotamos o referencial da Análise Institucional de René Lourau e Georges Lapassade, mais especificamente em uma perspectiva "no papel”. A referida perspectiva teórica, metodológica e epistemológica se caracteriza por ser um método de conhecimento em que se busca uma análise econômica, política, funcional, estrutural e estruturo-funcional dos processos sociais que nos circundam, tendo a ideia de instituição como um elemento fundante de análise dessas práticas sociais (LOURAU, 1995). Esse tipo de análise se inspira em intervenções e pesquisas no campo, tendo um relativo destaque pela possibilidade de agregar materiais, elucidações teóricas, além de maneiras de avaliação e de critérios de validade (LOURAU, 1995). Nessas modalidades de pesquisa, alguns conceitos importantes dizem respeito aos seguintes: campo de análise; campo de intervenção e analisador.

Enquanto o campo de análise se funda no entendimento dos grupos como totalmente atravessado pelas instituições que os cercam, o campo de intervenções, por outro lado, diz respeito a criar um dispositivo de análise social coletiva, promovendo, desse modo, a autoanálise e a autogestão dos grupos com os quais se atua. Por fim, os analisadores podem ser compreendidos como aqueles que nos permitem provocar os conteúdos outrora implícitos das instituiçóes, fazendo-os ver e falar (LOURAU, 2004).

No caso de nossa investigação, nosso campo de análise é constituído pelas compreensóes da Umbanda sobre saúde, adoecimento e cuidado, campo este totalmente atravessado pelas instituições saúde, religião e cuidado. Por outro lado, nosso campo de intervenção foi tecido no cotidiano onde se encontram inseridos os líderes, os praticantes e os consulentes dos referidos estabelecimentos sagrados. De modo mais específico, a referida investigação aconteceu em três terreiros de Umbanda de uma cidade do interior do Piauí. A seleção dos estabelecimentos religiosos não obedeceu a qualquer espécie de critérios previamente definidos. Em linhas gerais, o processo se desenrolou do seguinte modo: utilizando como intermediários alguns amigos, entramos em contato com as lideranças religiosas e, a partir delas, com os terreiros de Umbanda propriamente ditos. 
É importante ressaltarmos que duas das casas espirituais eram conduzidas por mulheres (Ashanti e Mmaabo). ${ }^{9}$ Ambas eram negras, tinham aproximadamente 60 anos de idade e realizavam suas atividades espirituais em salóes construídos nos quintais das suas próprias residências. Ao contrário delas, o terceiro centro religioso era conduzido por um homem de aproximadamente 45 anos de idade (Azekel) e possuía como característica principal o fato de funcionar em um espaço exclusivamente reservado para essa função.

As regióes em que se encontram as casas espirituais investigadas guardavam algumas semelhanças entre si. A primeira delas diz respeito ao fato de os bairros estarem localizados em regiōes consideradas "antigas" da cidade: enquanto dois deles tiveram suas origens nos arredores da Colônia do Carpina, mais conhecida anteriormente como leprosário, o outro surgiu em virtude de um programa de distribuição de casas populares realizado pelo então governador do estado.

Outras características apresentadas pelas regióes em que esses estabelecimentos estavam localizados eram as seguintes: altos níveis de violência urbana; péssimas condiçôes de infraestrutura, tais como calçamentos quebrados, algumas ruas de areia e uma ínfima quantidade de postes com iluminação noturna; e dificuldade no acesso a essas regiôes, principalmente em virtude dos poucos transportes públicos que faziam rotas até os respectivos bairros - problema este que se confunde com a situação crônica que atravessa a própria cidade em estudo.

Para alcançarmos nosso objetivo, fizemos uso de entrevistas semiestruturadas com três líderes dos centros religiosos umbandistas (Ashanti, Mmaabo e Azekel; todos os nomes são fictícios e de origem africana); observação participante de algumas das cerimônias religiosas em que as casas espirituais conduzidas por esses sujeitos ofertavam espaços de cura; cuidado em saúde, aconselhamento e orientação espiritual à população de forma geral; e conversas informais com os praticantes e consulentes dos respectivos espaços sagrados.

De modo geral, nos inserimos como consulentes, semanalmente, nas atividades dos respectivos terreiros de Umbanda. Em decorrência das especificidades nos dias e horários de funcionamento de cada um dos terreiros investigados, não houve uma equivalência na quantidade de visitas, conforme pôde ser visualizado na tabela abaixo: 
Tabela 1. Dias de imersão nos terreiros investigados

\begin{tabular}{lll}
\hline TERREIROS & FUNCIONAMENTO & IMERSÃO \\
\hline Ashanti & $\begin{array}{l}\text { Consulente é atendido a qualquer momento que } \\
\text { chegue, independentemente do dia e horário. }\end{array}$ & $\begin{array}{l}\text { Não acompanhamos } \\
\text { as práticas de cuidado } \\
\text { em saúde }\end{array}$ \\
\hline Mmaabo & Duas vezes por semana no horário da tarde. & oito visitas \\
\hline Azekel & Uma vez por semana (três vezes por mês). & três visitas \\
\hline
\end{tabular}

Fonte: elaboração própria.

É válido ressaltarmos que durante nossa caminhada obedecemos às normas e aos procedimentos éticos relativos às pesquisas envolvendo seres humanos, em acordo com as resoluções no 466/2012 e no 510/2016, ambas do Conselho Nacional de Saúde (CNS). Por fim, destacamos também que a presente investigação foi submetida ao Comitê de Ética em Pesquisa (CEP) da Universidade Federal do Piauí (UFPI), Campus Ministro Petrônio Portella, e obteve parecer favorável para sua execução sob o CAAE no 79267617.7.0000.5214.

\section{Resultados e Discussão}

Ao redor da Umbanda estão instituídas compreensôes particulares sobre as mais variadas questôes referentes à nossa existência, tais como nascimento, morte, saúde, adoecimento e cuidado. Nesse sentido, os processos de saúde/doença/cuidado seriam apenas um pequeno analisador em uma rica tradição simbólico-cultural. Durante nosso percurso investigativo, pudemos compreender que diversas questóes explicariam, na concepção dos adeptos/consulentes dessas doutrinas religiosas, as situaçôes de adoecimento de ordem física, psicológica ou espiritual. Uma primeira questáo diz respeito à assertiva, instituída em alguns terreiros, de que nós, seres humanos, seríamos um grande campo energético.

Ao tomar como embasamento essa afirmaçáo, podemos recorrer ao que diz Pai Légua, divindade cultuada em um dos centros religiosos investigados, mais especificamente quando o mesmo, em uma das consultas que tivemos com ele, discorreu sobre uma energia espiritual concentrada em determinadas regióes dos nossos corpos e que, em desequilíbrio, provocariam dores, sofrimentos e afliçóes. 
Seria sobre esse campo energético que os Orixás e demais divindades umbandistas iriam trabalhar, principalmente com o objetivo de promover uma cura ou um suporte psicossocial diante das doenças de ordem física, psicológica ou espiritual que afligem os seus consulentes. Cura essa que, diferentemente do que almeja o saber racional-cartesiano-positivista, é gradual, não tem pressa, podendo demorar seis meses, como também dois anos, uma década, ou quem sabe, nunca ter uma solução definitiva.

Segundo Azekel, condutor do terreiro em que Pai Légua atua, muitos dos nossos pensamentos reverberam nesse campo energético, de modo que, na concepção do mesmo, as pessoas que possuem pensamentos negativos irão atrair para si coisas consideradas ruins, tais como angústias, aflições, desentendimentos nos relacionamentos e até mesmo doenças físicas ou espirituais. Na concepção dessa figura-chave, muitos chegam ao seu terreiro em busca de auxílio para a cura das doenças que os afligem, julgando que tais condiçóes decorrem de algum trabalho espiritual feito por alguém, quando, na realidade, seria resultado da maneira como ela se comporta e enxerga o mundo. Nesse sentido, afirmamos que compreender os processos de saúde-adoecimento sob o prisma de um campo energético significa que no interior dos circuitos umbandistas imperam cosmologias que atestam o processo de adoecer como decorrente não apenas de uma massa anátomo-fisiológica, mas também de um campo energético que, em maior ou menor medida, estaria relacionado a uma energia psíquica e, portanto, aos afetos.

A partir dessa compreensão instituída sobre os processos de saúde/adoecimento dentro dos circuitos da Umbanda, e que se mostrou perceptível nos discursos de Pai Légua e Azekel, é possível recorrer ao pensamento do filósofo Baruch Spinoza, mais especificamente quando o mesmo afirmou que o corpo humano, ao ser afetado, tem sua potência de agir aumentada ou diminuída, produzindo, em decorrência disso, afetos considerados alegres ou tristes. Nesse aspecto, as paixôes alegres e tristes surgiriam a partir de encontros que teriam o poder de aumentar, diminuir ou destruir nossas potências de existir, de agir e de pensar (SPINOZA, 2009).

A partir disso, podemos concluir que durante as 24 horas do dia não conseguimos vivenciar apenas paixôes alegres ou tristes. Elas constantemente se interpenetram e se intercruzam, adquirindo características bastante peculiares: determinados encontros aumentarão nossa potência de vida, enquanto que, em outros casos, esta será destruída. E assim se produzirão as agruras instituídas em nosso cotidiano. 
Entretanto, não devemos compreender essas duas categorias como um movimento dialético em que os sujeitos quando doentes não poderiam ser saudáveis ou viceversa. Tomando como premissa essa afirmação, é possível resgatarmos os escritos de Deleuze (2002), que, ao discorrer sobre o pensamento de Nietzsche, afirma que a Grande Saúde seria um processo de deslocamento de perspectivas em que os sujeitos poderiam tanto fazer dos seus momentos de adoecimento um ponto de vista sobre a saúde, como também, no auge de uma vida rica, superabundante e segura de si, mergulhar no trabalho secreto da decadência e da doença.

Poderíamos presumir que uma vida considerada "normal” deveria ser recheada por uma certa mobilidade, de modo que, nos momentos de angústia e desamparo, encontraríamos sinais de saúde e vigor e, por outro lado, nas circunstâncias em que estivéssemos satisfeitos conosco mesmos e com nossa saúde, seria possível nos deparar com indícios de adoecimentos (DELEUZE, 2002).

De certo modo, essa compreensão filosófica de saúde-doença não se encontra muito distante das racionalidades instituídas no interior dos circuitos umbandistas, já que nesses estabelecimentos sagrados também se encontra instituída a compreensão de que os processos de saúde/doença não são considerados categorias retilíneas, em que supostamente os sujeitos estariam completamente "curados" das afliçôes que os atingiriam, ou que, por outro lado, quando estivessem na posição de curadores, esses indivíduos não passassem por questôes pessoais e/ou espirituais que necessitassem ser atendidas também nesses estabelecimentos sagrados.

A partir dos discursos mencionados, pudemos, portanto, perceber que uma das integibilidades sobre saúde, adoecimento e cuidado dos praticantes e consulentes da Umbanda afirma que estas não são categorias estanques e retilíneas, mas, pelo contrário, pertencem a um continuum que estaria instituído nas existências dos sujeitos e das coletividades, onde todas essas questôes estariam manifestas de modo ramificado e difuso.

Ao darmos prosseguimento a nossas problematizaçóes, deparamo-nos com um discurso de Ashanti: para ela, esses processos de saúde-doença aconteceriam por causa das más condutas que as pessoas tiveram em tempos passados, sejam eles durante essa existência carnal ou em outras. A solução por detrás das nossas agruras cotidianas, para a referida entrevistada, estaria na constante busca por Deus. É o que podemos visualizar no excerto a seguir: 


\begin{abstract}
Ashanti: Então, por que tem muitas pessoas que se enforca? Muitas pessoas que se jogam embaixo de um carro? "Meu Deus! O que aquela pessoa viu? Era uma pessoa táo boa e se tornou daquele jeito". Alguma coisa ruim ele fez pra trás.... Então... Existe uma força maior, que é Deus... É o único justo... É Ele. E são poucas pessoas que acreditam Nele, porque a maioria das pessoas só pensa em dinheiro, não pensa no amor de Deus, mas quando você tem o amor de Deus dentro do seu coração, você é uma pessoa maravilhosa, você não tem maldade, você cresce e todo dia. Deus abre uma porta pra melhorar sua vida.
\end{abstract}

A partir dessa narrativa, podemos recorrer ao que diz Michel Foucault quando o mesmo disserta sobre o pastorado, o qual, de acordo com o referido filósofo, seria caracterizado principalmente por possibilitar aos sujeitos e às comunidades a oportunidade de trilharem o caminho em direção à salvação, percurso esse que somente seria conquistado quando tais atores se submetessem às ordens e aos mandamentos instituídos pela Igreja, considerando-os como a verdade a ser seguida (salvação, lei e verdade) (FOUCAULT, 2008).

Para o Cristianismo, não seguir essas premissas poderia ocasionar a ira divina, que se abateria nos sujeitos e na comunidade na forma de castigos, os quais poderiam assumir muitas formas, tais como falta de sorte, furo ocasional no pé (conforme veremos adiante) ou adoecimentos físicos ou espirituais. Processo semelhante visualizamos na Umbanda: em nosso entendimento, concebido a partir do que temos visualizado até então, não seguir os ditames proferidos por essas doutrinas não seria, portanto, apenas um pecado, mas também algo passível de dor e doenças, visto que não agradaria às divindades superiores, tais como Deus e os Orixás.

Tal assertiva também pôde ser constatada durante uma das nossas idas ao terreiro de Mmaabo. Na ocasião, conversávamos com algumas mulheres (Ayana, Ashaki e Badu) que conhecíamos apenas de vista. Pelo pouco que sabíamos, as distintas figuras não assumiam apenas a função de consulentes, visto que também frequentavam outras cerimônias religiosas realizadas pelo terreiro.

Em determinado momento do nosso diálogo com as distintas personagens, Ayana começou a falar para suas companheiras que a cerimônia da noite anterior não havia acontecido porque o esposo de Mmaabo havia furado o pé com um prego que estava solto pelo quintal. Segundo a adepta, isso havia sido um castigo dos Orixás, porque minutos antes, o mesmo havia falado que o local estava arrumado para alguma festa junina, quando na verdade era por causa do festejo de São Sebastião, que aconteceria no dia seguinte, evento esse muito aguardado por todos, visto que, além do aniversário do santo, também seria o da condutora do terreiro, de modo que 
uma grande comemoração estava prevista para acontecer. Entretanto, além desses analisadores, durante nossa jornada investigativa também conseguimos identificar, e compreender em suas nuances, outros que também se relacionavam com as inteligibilidades sobre saúde/adoecimento/cuidado dos adeptos e consulentes dos três terreiros de Umbanda em que realizamos nosso estudo. São eles: nervosismo; espíritos ruins, também conhecidos como obsessores; e mediunidade não desenvolvida.

De imediato, antes mesmo de mergulharmos em cada um desses analisadores, é importante novamente ressaltarmos o fato de que tais compreensôes abdicam dos discursos que as concebem como tendo uma natureza localizável, como é o caso das ideias da fisiologia, da mecânica, da autorregulação e do equilíbrio dinâmico, para, ao invés disso, compreender as situaçóes de saúde-adoecimento como decorrentes de experiências modificadoras em nossas potências de vida (ou energéticas, como queiram chamar) (CONCEIÇÃO; FRANCO, 2017).

Durante nossa jornada, em alguns momentos tivemos a oportunidade de nos deparar com um fenômeno que as classes populares de forma geral, e não apenas os adeptos e consulentes das religióes umbandistas, concebem como sendo "nervoso" ou "nervosismo". Em determinada tarde, quando estávamos no quintal da casa de Mmaabo esperando que as consultas tivessem início, eis que chega um homem com um menino de aproximadamente 10 anos.

A criança era relativamente grande, contudo era extremamente magra. Vez ou outra, alguma pessoa se referia ao problema do garoto como de "nervoso" e que não era para ele "se impressionar" muito com as coisas. A presença de uma criança logo comoveu os demais consulentes de modo que táo rápido o rumo da conversa passou a ser sobre os "humores de uma criança": "quando é muito quieta, a gente tem que desconfiar", foi a conclusão da roda. Desse modo, um fator a ser acrescentado à discussão diz respeito ao fato de que determinados modelos em saúde se contrapóem não só à perspectiva biomédica, mas também objetivam superar os pressupostos da ideologia do individualismo que sustenta o senso comum na cultura ocidental moderna. Em vez da defesa dos especialismos presentes, por exemplo, nas dicotomias entre razão/emoção ou corpo/espírito (DUARTE, 1998), temos assistido a um movimento de pesquisadores do campo da saúde, ainda embrionário, que tem embasado epistemologicamente seus estudos em autores da Antropologia Social Brasileira. 
É o caso do antropólogo Luiz Fernando Dias Duarte e suas teorizaçóes sobre as perturbaçôes nas classes populares brasileiras, sobretudo no tocante às representaçôes da categoria nervoso. Para o referido autor, as situaçôes de adoecimento dos sujeitos e das coletividades tratar-se-iam, na realidade, de perturbaçôes físico-morais, as quais poderiam ser compreendidas como as "condiçôes, situaçôes ou eventos de vida considerados irregulares ou anormais pelos sujeitos sociais e que envolvem ou afetam não apenas sua mais imediata corporalidade, mas também sua vida moral, seus sentimentos e sua autorrepresentação" (DUARTE, 2003, p. 177).

O fio central da argumentação de Duarte (2010) se estabelece na demonstração de que as formas de construção das pessoas nas classes populares não obedecem aos mesmos princípios do individualismo, de modo que suas perturbaçóes físico-morais se estruturam distintamente ao instituído nos meios letrados e dominantes de nossa sociedade, estes últimos caracterizados pelos seguintes aspectos: racionalização; afastamento do sensível; fragmentação e universalização dos domínios dos saberes; interiorização e psicologização dos sujeitos.

Esses mesmos consulentes anteriormente mencionados, em outros momentos, também relataram conceber determinadas moléstias como oriundas do trabalho espiritual feito por obsessores ${ }^{10}$ sob encomenda de alguém, compreensão essa que também destoa dos modelos biomédicos e psicologizantes instituídos em nossa sociedade, já que se fundamenta numa explicação espiritual para compreender determinados processos de saúde-doença.

Como ilustração, podemos mencionar uma conversa que tivemos com algumas mulheres que buscavam por atendimentos no terreiro de Mmaabo: neste diálogo, elas nos narraram a história de um homem que aparentemente estava possuído por um obsessor. Segundo essas consulentes, o sujeito havia aparecido numa tarde de atendimentos no terreiro. Estava bastante exaltado, de modo que duas ou três pessoas o carregavam. Assim que ele chegou, a condutora da casa - que na ocasião estava incorporada pelo espírito de uma preta velha ${ }^{11}$ chamada de Vovó Catarina de Angola - pediu para que todos os consultantes saíssem e fechassem o saláo, pois ela iria expulsar a divindade maligna que ali se encontrava.

O caso aparentemente gerou imensa fofoca e burburinho, até porque muitos dos telespectadores do acontecimento não eram iniciados na Umbanda, portanto, não sabiam maiores detalhes sobre o porquê do ocorrido. Em momento posterior, em conversa com Mmaabo, ela nos explicou que esse tipo de situação era bem frequente 
não apenas no terreiro dela, mas em muitos outros terreiros de Umbanda da cidade, sendo tais "forças malignas" denominadas por eles como "sombras":

Mmaabo: A sombra significa, ó, assim, se chega uma pessoa aqui muito doente, amarrado, como já tem costume de chegar aqui pessoa amarrada, aí a preta velha diz: 'zombeteiro'. Zombeteiro é uma coisa ruim. Assim, faz a pessoa beber, faz a pessoa fumar, faz a pessoa matar, faz a pessoa morrer, é o zombeteiro. Que tá na vida daquela pessoa. Anda com ele todo o tempo, né, pra ele fazer aquilo dali e a pessoa que veio aqui, ele ouvia voz, a voz dizia assim: "Vá lá em fulano de tal matar ele. Mata ele que tu vai te salvar".

Por outro lado, também nos deparamos com discursos que associavam determinadas situaçóes de adoecimentos como resultados de uma mediunidade ${ }^{12}$ não desenvolvida, conforme pudemos identificar, em determinados momentos, em algumas falas de Azekel, bem como em algumas consultas realizadas no terreiro de Mmaabo, como por exemplo, na situação em que uma das consulentes da casa (Homa) alegou ter desmaiado num terreiro por conta das roupas "esquisitas e estranhas" que os adeptos usavam.

$\mathrm{Na}$ referida ocasiáo, ela nos confidenciou que toda sua família "era ligada com macumba", ${ }^{13}$ sendo que determinados parentes, como era o caso de sua tia, inclusive tinham um terreiro sob seu comando. Contudo, nem ela nem o pai gostavam de ser atendidos no referido local, pois "por lá os irmãos não são unidos, é um querendo acabar com o outro. Já fizeram trabalho para minha mãe só porque ela chegou atrasada". Pouco tempo depois, a matriarca virou evangélica e, segundo Homa, ela passou a frequentar muito menos terreiros umbandistas, só voltando a fazer isso após a morte da mãe.

Homa também falou que os seus desmaios eram frequentes, de forma que ela já precisou ser levada na calada da noite para a casa de Mmaabo com o objetivo de ser socorrida. Entretanto, conforme menciona a referida líder religiosa, esses casos de adoecimentos eram mais frequentes do que se esperava, de modo que tal situação não era exclusiva de Homa.

Após dissertarmos sobre os analisadores anteriormente mencionados, é possível perceber que as compreensóes em torno dos processos de saúde/adoecimento/ cuidado estão circunscritas em compreensôes que são a um só tempo sociais, históricas, econômicas, políticas, religiosas e culturais, que em muito convergem com os determinantes sociais da saúde, mais especificamente no que concerne à Promoção da Saúde. 
É o caso de uma das líderes religiosas entrevistadas, mais especificamente Ashanti, a qual dissertou sobre a importância do dom da mediunidade nas compreensões dos umbandistas sobre saúde, doença e cuidado, visto que é graças a esse dom que ela pôde aprender mais sobre os processos de saúde, adoecimento e cuidado. Eis algumas palavras proferidas por ela:

Ashanti: Aí, o que é que acontece? Eu fui crescendo, crescendo, e aquela energia, ela se transportava, ela mudava, o meu corpo mudava. [...]. Eu não tive os professores. Os meus professores foram o mundo e os meus Orixás. Aprendi com o vento, com a força da terra e do Oriente. Esse, eu aprendi, porque esses são os verdadeiros ensinamentos, que eu não precisei do professor para isso e os meus professores foram os meus Orixás, (des) conhecedor de várias pessoas, que nem todo mundo conhece o que é um Orixá, nem todo mundo conhece o que é um espírito, acha que tudo é fantasia da cabeça da gente, mas não é fantasia da cabeça da gente, porque eu também pensava que isso era uma fantasia.

Podemos, então, perceber o quanto os médiuns (isto é, as pessoas que são capazes de se comunicar com mundo espiritual) têm uma importância significativa nas práticas de cuidado em saúde ofertadas pela Umbanda, uma vez que os corpos dos praticantes servem de abrigo para que as divindades estabeleçam relaçóes com o mundo dos humanos. Nesse sentido, é necessário haver muito conhecimento e preparação até que, finalmente, o médium se considere como apto para participar das cerimônias através da incorporação das divindades sagradas e da consequente oferta do cuidado em saúde aos consulentes que se dirigem aos terreiros em busca de ajuda (ZANGARI, 2005).

Contudo, tal caminhada em direção a se tornar um cuidador nem sempre é uma tarefa fácil, sendo considerada por muitos como algo sofrido e que provoca estranhamentos. É o que nos afirma Ashanti através de um excerto da nossa entrevista:

Ashanti: [...] Eu comecei na Umbanda eu tinha.... sete anos. Eu era pequenininha, tinha visóes. Às vezes eu não dormia, via pessoas, mas porque eu via alguém falar, as folhas falavam comigo. Então, até aí eu achava que eu era louca: “isso é coisa de louco”. Aí eu fui crescendo, né, tendo visóes, às vezes eu desmaiava, às vezes eu tava conversando com você, de repente eu tava falando diferente, eu sentia que minha voz tava mudando, eu já não falava como criança, eu já tava falando como um adulto [...].

Um primeiro aspecto importante de ser ressaltado no que concerne a esse analisador diz respeito ao papel que a referida mãe de santo ${ }^{14}$ desempenha nos terreiros que conduz: para ela, tornar-se uma cuidadora é uma tarefa árdua e com a presença de chagas, as quais se mostram perceptíveis desde muito cedo, como por exemplo nas circunstâncias em que elas foram tidas como bruxas, loucas e que 
adoravam o demônio na visão cristã. Por conta dessa encomenda de normalidade por parte da sua família, não apenas Ashanti como muitas outras médiuns também foram internadas em hospitais psiquiátricos ou violentadas física, psicológica e verbalmente, passando a serem alvos de processos de discriminaçóes cotidianas, seja no âmbito da família, escola ou trabalho. Desse modo, podemos perceber que a figura do cuidador apresenta úlceras tão intensas ou mais profundas que as dos seus hóspedes que trazem como encomenda a cura para questôes de ordem física, psicológica ou espiritual: são, pois, cuidadores feridos. De modo geral, para melhor compreendermos quem são esses sujeitos, é importante que lancemos olhares para a figura do orixá Omolu, também chamado de Obaluaê, Xapanã ou Sapatá.

Nas tradições africanas, Omolu é representado por uma cobertura de palha comprida que reveste o seu corpo com o objetivo de ocultar as diversas chagas provocadas pela varíola em sua infância, como resultado de conflitos com sua máe. Além disso, esses ferimentos também foram causados pelas dificuldades vividas quando deixou sua casa para procurar seu próprio caminho, momentos nos quais passou fome e sede, além de ter sido vítima de rejeição por causa das suas úlceras (VASCONCELOS, 2003).

Essa experiência em lidar com as próprias dores e doenças o capacitou para ser um curador: carregando, então, vários tipos de águas, remédios e cabacinhas de poçóes, passou a visitar as comunidades onde fora rejeitado e nas quais os habitantes agora encomendavam cuidado diante de suas agruras cotidianas. Ele curava todos os doentes, bem como fazia um ritual de proteção, varrendo a peste para fora das casas com sua vassoura de fibras de coqueiro, o xaxará (VASCONCELOS, 2003).

Esses mesmos rituais de proteção e cura aos doentes são realizados em diversos terreiros ao redor do Brasil, conforme discorrem Gomes (2010), Mota e Trad (2011), Mello e Oliveira (2013), Rios et al. (2013) e Silva, Fernandez e Sacardo (2017). Nesses materiais, não apenas os terreiros de Umbanda, mas também de outras religiôes afro-brasileiras, são apresentados como importantes espaços promotores de saúde e possíveis parceiros do Sistema Único de Saúde (SUS). Além disso, também com base nos discursos anteriormente explicitados, conseguimos identificar tênues limites que separam a mediunidade da loucura. Para muitas pessoas, alguém se declarar publicamente como sendo um "médico das almas", que ouve vozes e incorpora espíritos ancestrais, não é algo que, num primeiro momento, remeta 
à racionalidade positivista, biomédica e cartesiana; portanto, não transita entre a estreita e instituída faixa da normalidade.

No que concerne a esse assunto, recorremos a Georges Canguilhem, quando o mesmo afirma que uma média, obtida estatisticamente, não permite dizer se determinado sujeito, presente diante de nós, é normal ou não. Nas palavras do próprio autor, nossas existências não são consideradas categorias estanques e retilíneas, portanto, instituídas. Muito pelo contrário: nelas, é possível construirmos movimentaçôes instituintes a partir de rasgos, vazios, fugas, esquivamentos e reticências inesperadas (CANGUILHEM, 2010).

E no campo da saúde não seria diferente. Em vez de nos posicionarmos em favor de binarismos que tão somente nos encaixam em categorias diagnósticas de doente/ anormal ou sadio a depender de como pensamos e nos comportamos, apostamos no caráter contestatório dos processos de saúde/doença/cuidado, ou seja, questôes de ordem social, histórica, econômica, política e cultural caminhariam lado a lado, produzindo reverberaçóes em nossos modos de ser e de existir e, portanto, no que conceberíamos como saúde.

Dando prosseguimento a nossas problematizações, o que podemos perceber é que se tornar um cuidador é uma sina de nascença, um legado adquirido e que produz duras consequências em seus modos de ser e de existir, chegando, em muitos casos, a provocar estigmas, preconceitos, violências verbais e físicas, internações e, quem sabe, até a morte. Nesse sentido, não tem como colocarmos do mesmo lado da balança os cuidadores hegemônicos, considerados "oficiais" por grande parte da sociedade (tais como médicos, psiquiatras, enfermeiros e psicólogos) e os que produzem saúde a partir das suas respectivas fés e que desde pequenos foram marcados na missão que os esperava, já que são duas racionalidades concernentes ao produzir saúde. De um lado, compreensóes sustentadas majoritariamente por um modelo cartesiano, biomédico e positivista, e, do outro, inteligibilidades circunscritas à espiritualidade e aos saberes tradicionais, como africanos e indígenas.

É importante ressaltar que isso não quer dizer que os sacerdotes desta pesquisa desconsideravam as compreensóes da Medicina "oficial" sobre os processos de saúde, doença e cuidado. Inclusive, foi relatado pelos três sacerdotes da pesquisa que determinadas situaçôes de saúde têm explicaçôes de ordem física ou psicológica, sendo que, nesses casos, um tratamento com médicos, enfermeiros e psicólogos seja mais adequado. 


\section{Considerações finais}

A partir dos elementos expostos até aqui, podemos perceber que as concepçóes de saúde, adoecimento e cuidado produzidas pelos praticantes e consulentes da Umbanda compõem uma tradição milenar que mostra sua força desde muito antes de os portugueses imigrarem para as terras brasileiras. Por conta disso, não é de se admirar que suas cosmologias em muito destoem daquelas em que se sustentam os conhecimentos hegemonicamente instituídos que direcionam os profissionais da saúde.

Nesse sentido, para os líderes, consulentes e praticantes que fizeram parte desta pesquisa, os processos de saúde-doença não se limitariam a explicaçôes de cunho anatômico e fisiológico, como comumente encontramos instituídos no campo da saúde, mas também seriam devidas a outras questóes, tais como vimos no decorrer desse estudo. Desse modo, situações como desmaios, dores de ordem física ou o escutar vozes também poderiam ser explicados pelos seguintes aspectos: energia espiritual em desequilíbrio; más condutas que as pessoas tiveram em tempos passados, sejam eles durante essa existência carnal ou em outras; situaçôes de nervosismo; a influência de espíritos ruins; mediunidade não desenvolvida; e questôes de cunho médico ou psicológico.

A partir disso, pudemos perceber o quanto as compreensóes sobre saúde, adoecimento e cuidado dos líderes, praticantes e consulentes dos terreiros de Umbanda analisados estão circunscritas às cosmologias africanas, indígenas, católicas e espíritas, culturas estas que tiveram grande contribuição na constituição da religião umbandista. Cabe, portanto, a nós, profissionais de saúde, na nossa micropolítica do trabalho vivo, compreender as singularidades dos usuários umbandistas, de modo a respeitar os seus entendimentos sobre as situações de saúde que os circunscrevem.

Por fim, recomenda-se aos futuros pesquisadores que, a partir dessas compreensões sobre saúde, adoecimento e cuidado, possam ser pensados dispositivos conjuntos de diálogo e interface de cuidado em saúde entre profissionais e terreiros de Umbanda. Tarefa esta que, apesar de bastante desafiadora, mostra-se de imensa importância, em virtude da escassez dos estudos sobre a temática. ${ }^{15}$

\section{Referências}

BARROS, M. O candomblé bem explicado (Naçôes Bantu, Iorubá e Fon). Rio de Janeiro: CIPBRASIL, 2009. 
CANGUILHEM, G. O normal e o patológico. Tradução de M. T. R. C. Barrocas. 6a ed. Rio de Janeiro: Forense Universitária, 2010.

CASTRO, Y. P. O tráfico transatlântico e a distribuição da população negra escravizada no Brasil Colônia. Revista Digital Africanias, v. 12, p. 1-12, 2012. Disponível em: http://www. africaniasc.uneb.br/pdfs/n_2_2012/ac_03_castro.pdf. Acesso em: 3 ago. 2018.

CONCEIÇÃO, H. R. M.; FRANCO, T. B. Tensóes no conceito de saúde a partir de Nietzsche: a grande saúde e a produção do cuidado. Saúde em Redes, v.3, n. 1, p. 63-69, 2017.

DELEUZE, G. Espinoza: Filosofia Prática. São Paulo: Escuta, 2002.

DIAS, R. N.; BAIRRÃO, J. F. M. H. Aquém e Além do cativeiro dos conceitos: perspectivas do preto-velho nos estudos afro-brasileiros. Memorandum, v. 20, p. 145-176, 2011.

DUARTE, L. F. D. Indivíduo e pessoa na experiência da saúde e da doença. Ciência \& Saúde Coletiva, v. 8, n. 1, p. 173-183, 2003.

. O nervosismo como categoria nosográfica no começo do século XX. História, Ciências, Saúde-Manguinhos, v. 17, supl. 2, p. 313-326, 2010.

. Pessoa e dor no Ocidente (O "holismo metodológico" na antropologia da saúde e da doença). Horizontes Antropológicos (Porto Alegre), v. 4, n. 9, p. 13-28, 1998.

FOUCAULT, M. Segurança, território e população: Curso dado no Collège de France (19771978). Tradução de E. Brandão. São Paulo: Martins Fontes, 2008.

FREITAS, M. S. Refletir sobre a História do Negro no Brasil: uma resposta ao racismo. In: CONGRESSO DE EDUCAÇÃO, II., Universidade Estadual de Goiás, Iporá, GoiásGO, 2012 .

GOMBERG, E. Hospital dos Orixás: encontros terapêuticos em um terreiro de candomblé. Salvador: EDUFBA, 2011.

GOMES, M. C. P. A. Projeto: Ylê ayié yaya ilera (Saúde plena na casa desta existência): equidade e integralidade em saúde para a comunidade religiosa afro-brasileira. Interface: Comunicação Saúde Educação, v. 14, n. 34, p. 663-772, 2010.

JENSEN, T. G. Discursos sobre religiōes afro-brasileiras: da desafricanização para a reafricanização. Revista de Estudos da Religião, n. 1, p. 1-21, 2001.

LOURAU, R. A análise institucional. Tradução de M. Ferreira. Petrópolis: Vozes, 1995.

. Uma apresentação da análise institucional. In: ALTOÉ, S. (Org.). René Lourau: analista institucional em tempo integral. São Paulo: Hucitec, 2004, p. 128-139.

MELLO, M. L.; OLIVEIRA, S. S. Saúde, religião e cultura: um diálogo a partir das práticas afro-brasileiras. Saúde \& Sociedade, v. 22, n. 4, p. 1024-1035, 2013. 
MOTA, C. S.; TRAD, L. A. B. A gente vive pra cuidar da população: estratégias de cuidado e sentidos para saúde, doença e cura em terreiros de Candomblé. Saúde e Sociedade, v. 20, n. 2, p. 325-337, 2011.

RIBEIRO, J. O. Sincretismo religioso no Brasil: uma análise histórica das transformaçóes no catolicismo, evangelismo, candomblé e espiritismo. Trabalho de Conclusão de Curso (Graduação em Serviço Social) - Universidade Federal de Pernambuco. Recife, Pernambuco, 2012.

RABELO, M. C. M.; ARAGÃO, R. Caboclos e Orixás no Terreiro: modos de conexão e possibilidades de simbiose. Religião \& Sociedade, v. 38, n. 1, p. 84-109, 2018.

RIOS, L. F. et al. Axé, práticas corporais e Aids nas religióes africanistas do Recife, Brasil. Ciência \& Saúde Coletiva, v. 18, n. 12, p. 3653-3662, 2013.

RODHE, B. F. Umbanda, uma religião que não nasceu: breves consideraçôes sobre uma tendência dominante na interpretação do universo umbandista. Revista de Estudos da Religiáo, p. 77-96, 2009.

SCHWARCZ, L. M.; STARLING, H. M. Brasil: uma biografia. São Paulo: Companhia das Letras, 2015.

SILVA, R. A.; FERNANDEZ, J. C. A.; SACARDO, D. P. Para uma “ecologia de saberes” em saúde: Um convite dos terreiros ao diálogo. Interface (Botucatu), v. 21, n. 63, p. 921-931, 2017.

SILVEIRA, H. Tradiçóes de matriz africana e saúde: O cuidar nos terreiros. Identidade!, v. 19, n. 2, p. 75-88, 2014.

SPINOZA, B. Ética. Tradução de T. Tadeu. Belo Horizonte: Autêntica Editora, 2009.

VASCONCELOS, E. M. O poder que brota da dor e da opressão: empowerment, sua história, teorias e estratégia. Rio de Janeiro: Paulus, 2003.

ZANGARI, W. Uma leitura psicossocial do fenômeno da mediunidade de Umbanda. Boletim Academia Paulista de Psicologia, v. 15, n.3, 70-88, 2005.

\section{Notas}

${ }^{1}$ Pessoas que seguem os princípios e as doutrinas de determinada religião, como, no caso do estudo em questão, a Umbanda.

${ }^{2}$ Pessoas que buscam terreiros de Umbanda em busca de conselhos, orientaçóes e trabalhos de cura e cuidado em saúde. Nesses casos, o sujeito que solicita ajuda não precisa ser pertencente à referida religião.

${ }^{3}$ Local onde acontecem as cerimônias religiosas umbandistas.

${ }^{4}$ Figura responsável por capturar os negros fugitivos das fazendas ou feitorias. Eram responsáveis por sequestrar escravizados em fuga e devolvê-los aos seus donos em troca de recompensa.

${ }^{5}$ Pessoas responsáveis pelos engenhos produtores de açúcar durante o período colonial brasileiro. Os interessados nesse empreendimento recebiam as unidades açucareiras dos donatários e representantes da Coroa. 
${ }^{6}$ Comunidades formadas por pessoas escravizadas que fugiam dos seus respectivos locais de trabalho. Aos poucos, esses estabelecimentos se transformaram em centros de resistências dos africanos que escapavam do trabalho forçado no Brasil.

${ }^{7}$ Kongo e Iorubá são dois dos grupos étnicos africanos que vieram traficados para terras brasileiras.

${ }^{8}$ São considerados expressôes de seres divinos. Geralmente representam pontos de força da natureza, tais como as águas, a arte curativa ou a habilidade em guerrear. Cada divindade possui um sistema simbólico particular composto de cores, comidas, cantigas, rezas, oferendas, espaços físicos e horários.

9 Todos os participantes do estudo são apresentados com nomes fictícios. Além disso, optamos que os mesmos tivessem origens e significados relacionados a alguns dos idiomas africanos.

${ }^{10}$ Um espírito obsessor é aquele que se ocupa de causar transtornos e prejudicar a vida das pessoas.

${ }^{11}$ Os pretos velhos são divindades umbandistas que simbolizam os escravizados e, mais do que isso, o instituinte processo de resistência (tanto física quanto cultural) diante da opressão e diáspora sofrida (DIAS; BAIRRÃO, 2011).

${ }^{12}$ Capacidade de contato entre seres humanos e os espíritos.

${ }^{13}$ Apesar de popularmente ser utilizada como uma expressão pejorativa para se referir à Umbanda, para umbandistas, a palavra se refere a um antigo instrumento de percussão de origem africana, o qual é usado em alguns dos seus rituais.

${ }^{14}$ As expressões "mãe de santo" e "pai de santo" são utilizadas para se referir ao sacerdote ou sacerdotisa que comanda um terreiro de Umbanda.

${ }^{15}$ M. B. da Rocha realizou a pesquisa de campo e participou da redação do artigo. A. K. de S. Severo orientou a execução da pesquisa de campo e participou da redação do artigo. A. V. F. da Silva acompanhou o primeiro autor em algumas visitas ao campo, co-orientou e participou da escrita do artigo. 


\section{Abstract}

\section{The beats of drums in backyards: the understandings of Umbanda people on health, illness and care}

During the process of African enslavement in Brazil, blacks brought with them an immense symboliccultural background, such as dances, food, festivities and religious ceremonies. In the religious sphere, the process of exchanging African doctrines with cultural elements already existing in Brazilian lands gave rise to the Umbandaist religion. This article aimed to know the conceptions of practitioners and consultants of three Umbanda terreiros (meeting places) about health, illness and care. As a methodological matrix, we used the reference of Institutional Analysis "on paper". The participants were three Umbanda priests and their practitioners and consultants of the terreiros they conducted. As a result, we identified some elements that would explain, according to Umbanda cosmologies, the health / disease processes: energy imbalances; negative thoughts and conduct towards life; nervousness; obsessors; unresolved mediumship or any medical or psychological issue. Therefore, it can be seen that the knowledge of the Umbanda peoples on health is very different from those on which the hegemonically instituted knowledge that directs health professionals is based.

Keywords: Afro-Brazilian religions; cosmology; health; illness; care. 